\title{
COMMUNICATION
}

Cite this: DOI: 10.1039/x0xx00000x

Received 00th January 2012,

Accepted 00th January 2012

\section{Programmed stereoselective assembly of DNA-binding helical metallopeptides}

\author{
Ilaria Gamba, ${ }^{a}$ Gustavo Rama, ${ }^{a}$ Elizabeth Ortega-Carrasco,${ }^{b}$ Jean-Didier \\ Maréchal, ${ }^{b}$ M. Eugenio Vázquez ${ }^{c^{*}}$ and Miguel Vázquez López ${ }^{a^{*}}$
}

DOI: $10.1039 / \times 0 \times x 00000 x$

www.rsc.org/

A flexible and versatile synthetic approach for the construction of water-stable DNA-binding chiral peptide helicates and that is based in the solid phase peptide synthesis (SPPS) methodology is reported.

The development of non-natural agents that can reproduce the DNA recognition properties of natural transcription factors remains a major goal in biological chemistry, ${ }^{1}$ as they might have a great impact in fundamental and applied biological research, and even lead to the development of gene-targeted therapies. $^{2}$ Most of the efforts in this area have been directed towards the development of small organic binders, but in the past few years there has been a growing interest in the use of coordination and metallo-supramolecular compounds with unique structural and spectroscopic properties.

Helicates have shown promising and unusual DNA-binding properties, ${ }^{4}$ including major groove binding, ${ }^{,}$and recognition of DNA three-way junctions. ${ }^{6}$ However, nearly 20 years after the pioneering studies by Prof. Jean-Marie Lehn, ${ }^{7}$ helicates are still not viable alternatives to traditional DNA-binding agents. The slow development in the biological chemistry of metal helicates ultimately derives from the lack of efficient and versatile methodologies for their enantioselective synthesis, ${ }^{8}$ which usually result in mixtures of isomers of difficult separation," insoluble or unstable species in water, ${ }^{10}$ and above all, lack of versatility for structural and functional optimization." Prof. Scott recently proposed a new synthetic approach to DNAbinding helicates based in the self-assembly of aldehydes and amines in the presence of $\mathrm{M}$ (II) ions that allows the formation of water-stable and optically pure helicates." Although this method represents a great improvement over the traditional routes, it does not guarantee the straightforward access to structural variants to efficiently study the chemical and functional space.

Given our experience in the study of DNA recognition agents, ${ }^{13}$ DNA-binding peptides, ${ }^{14}$ metallopeptides, ${ }^{15}$ and helicates, ${ }^{10}$ we decided to investigate into this problem by developing an alternative approach to DNA-binding chiral helicates. Herein we report our proposal, which potentially combines the biocompatibility, modularity and structural control of peptides with the synthetic flexibility and versatility of solid-phase peptide synthesis (SPPS) methodology, which allows the straightforward construction and modification of the helicates and, therefore, the easy optimization of their biophysical properties.

2,2'-bipyridine (Bpy) is a privileged chelator that leads to stable complexes with many metal ions that has been extensively used in coordination and supramolecular chemistry. ${ }^{16}$ Thus, we decided to synthesize a Bpy analog appropriately modified for its application in SPPS as the basic component of our peptide helicates. Hence, the Bpy unit was derivatized with 5-amino-3-oxapentanoic acid (O1Pen) as a Fmoc-protected achiral amino acid (Fmoc-O1PenBpy-OH, 1, Scheme 1). ${ }^{15}$

Following the synthesis of the amino acid building block, we designed a peptidic ligand capable of folding into a singlestranded dinuclear hairpin helicate; the selected peptide sequence contains six O1PenBpy units, which satisfy the coordination requirements of two octahedral metal centers, arranged in three sets (or substrands) of two consecutive Bpy residues connected through two short loops. The loops, whose structures have been previously optimized, ${ }^{15 \mathrm{~b}}$ are key components of this design, as they include a $\beta$-turn promoting [(D/L)-Pro]-Gly- sequence that preorganize the ligand and induce the folding of the peptidic chain into discrete dinuclear species, thus avoiding the formation of higher order and polymeric complexes in the presence of metal ions (Scheme 1).

In order to gain some information about the structural viability of our design, molecular modeling was performed on the $\mathrm{Fe}(\mathrm{II})$ helicate derived from the peptide ligand LL-H (Scheme 1). The system was optimized following a hierarchical protocol that consists in: 1) Molecular Dynamics simulation on the loops of the metalopeptide; 2) clustering of the resulting $\mathrm{MD}$, and 3) refinement by $\mathrm{QM} / \mathrm{MM}$ geometry minimization of the most populated cluster representatives (see ESI). The final calculation was performed with solvent and electronic 
embedding effects. The lowest energy model presents a helical geometry (Scheme 1) with both $\mathrm{Fe}(\mathrm{II})$ ions in octahedral configurations and the six bipyridine rings ordered around the metal centers. The first coordination sphere of the metal ions is barely constrained by the entire peptide framework, indicating that an excellent complementarity between organic and inorganic moieties is achieved in this design.

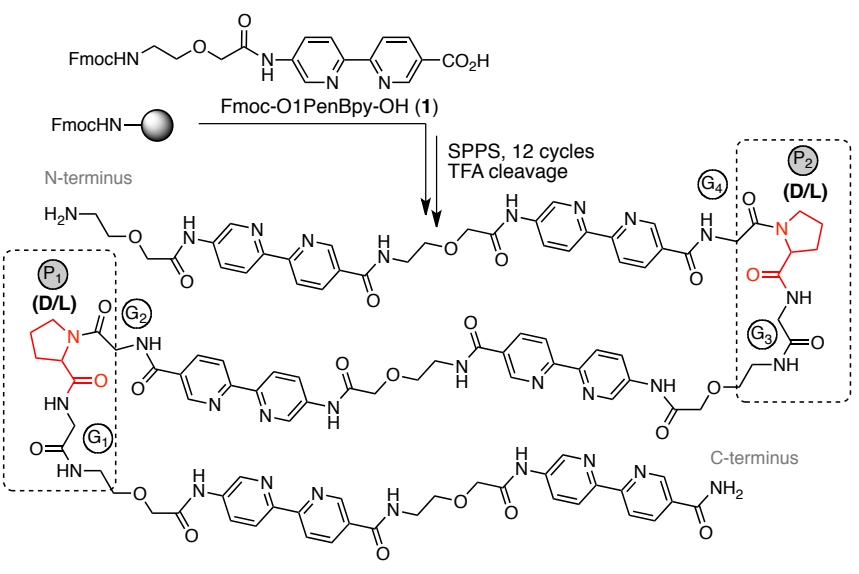

DD-H = H-(O1PenBpy) $)_{2}$-Gly-(D)Pro-Gly-(O1PenBpy) $)_{2}-$ Gly-(D)Pro-Gly-(O1PenBpy $)_{2}-\mathrm{NH}_{2}$ LL-H = H-(O1PenBpy) ${ }_{2}$-Gly-(L)Pro-Gly-(O1PenBpy) ${ }_{2}$-Gly-(L)Pro-Gly-(O1PenBpy) ${ }_{2}-\mathrm{NH}_{2}$
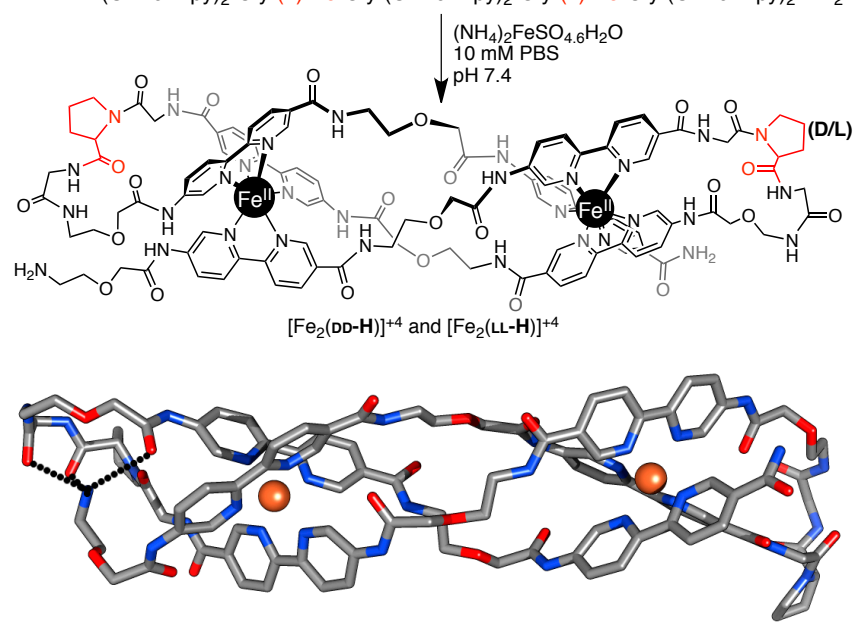

Scheme 1. Solid phase peptide synthesis of the peptide ligands LL-H and DD-H. Introducing of L-Pro or D-Pro residues in the loops selects a particular supramolecular chirality in the final helicates $(\Lambda-$ or $\Delta \Delta-$, respectively). Below, molecular representation of the most stable $M-\left[\mathrm{Fe}_{2}(\mathrm{LL}-\mathrm{H})\right]^{4+}$ helicate highlighting the interaction of the ammonium group of the $\mathrm{N}$-terminal end with the C-terminal loop.

Supported by the computational results, we synthesized the two enantiomeric peptide ligands, each of them equipped with two L-Pro (LL-H) or D-Pro residues (DD-H) in their loops (Scheme 1). Both peptidic strands were obtained following standard $\mathrm{Fmoc} / \mathrm{tBu}$ solid-phase protocols, ${ }^{17}$ and purified by reverse-phase HPLC (see ESI). Incubation of $4.0 \mu \mathrm{M}$ solutions of LL-H and DD-H in PBS buffer ( $\mathrm{pH}=5.1,298 \mathrm{~K}$ ) with increasing concentrations of $\mathrm{Fe}(\mathrm{II})$ resulted in a bathochromic shift of the bipyridine absorption band from 304 to $322 \mathrm{~nm}$, as well as in the appearance of a new band centered at $545 \mathrm{~nm}$, typical of octahedral trisbipyridine Fe(II) complexes (see ESI). The increase in the absorption intensity of the $\mathrm{d}-\mathrm{d}$ band was used to calculate the binding constants, which were the same within the experimental error for both LL-H and DD-H, ${ }^{18}$ thus for the first association $\beta_{1,1}(\mathbf{L L}-\mathbf{H}) \approx \beta_{1,1}(\mathbf{D D}-\mathbf{H}) \approx 12.9 \mu \mathrm{M}$, and the overall formation constants $\beta_{2,1}(\mathbf{L L}-\mathbf{H}) \approx \beta_{2,1}(\mathbf{D D}-\mathbf{H}) \approx 18.9$ $\mu \mathrm{M} .{ }^{19220}$ The successful assembly of the helicate, which can be considered as quantitative, was further confirmed by MALDITOF mass spectrometry showing a major peak at 2337.9 (see ESI). To our knowledge, SPPS has never been used for the preparation of helicates. Moreover, fully-peptide ligands have not been used before as precursors of metal helicates, and there are only a handful of examples of organic strands equipped with oligopeptides as spacers or functional appendages. ${ }^{2}$

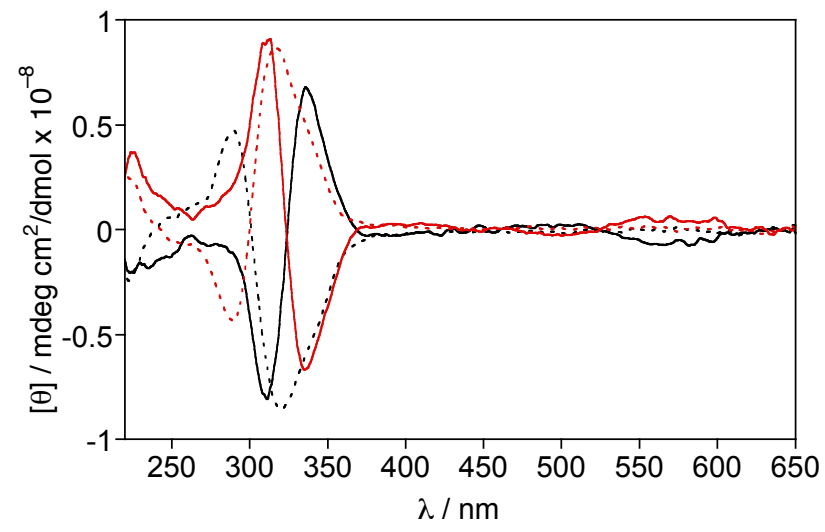

Figure 1. CD spectra of $\mathbf{L L}-\mathbf{H}$ and $\mathrm{DD}-\mathbf{H}$ peptide ligands $(50 \mu \mathrm{M})$ and their corresponding helicates. LL-H before (black dashed line) and after (black solid line, $M \Lambda-\left[\mathrm{Fe}_{2}(\mathrm{LL}-\mathrm{H})\right]^{4+}$ ) addition of 2 eq. of $\mathrm{Fe}(\mathrm{II})$ and $\mathrm{DD}-\mathrm{H}$ before (red dashed line) and after (red solid line, $\Delta \Delta-\left[\mathrm{Fe}_{2}(\mathrm{DD}-\mathrm{H})\right]^{4+}$ ) addition of 2 eq. of $\mathrm{Fe}(\mathrm{II})$. All measurements were made in PBS buffer $\mathrm{pH}=7.4,298 \mathrm{~K}$.

As expected, LL-H and its enantiomer DD-H give rise to mirror image CD spectra with two bands of opposite signs at approximately 290 and $324 \mathrm{~nm}$ with a crossover at $303 \mathrm{~nm}$ (Figure 1 and ESI). The intensity of these bands decreases upon addition of $\mathrm{Fe}(\mathrm{II})$, while at the same time they display a bathochromic shift to 302 and $333 \mathrm{~nm}$, respectively. The sign of the Cotton effect of the helicates is consistent with a $\Lambda$ configuration on each metal center for the LL-H derivative $\left(\Lambda \Lambda-\left[\mathrm{Fe}_{2}(\mathbf{L L}-\mathbf{H})\right]^{4+}\right)$, and a $\Delta$ - configuration for the DD-H analog $\left(\Delta \Delta-\left[\mathrm{Fe}_{2}(\mathbf{D D}-\mathbf{H})\right]^{4+}\right){ }_{.^{22}}$ These data confirm that the enantiomeric peptide ligands give rise to the enantiomeric helicates. ${ }^{23}$ This means that the chiral proline residues do not only direct the folding of the peptide chain into a discrete dinuclear helicate, but also encode its chirality, which is selected under thermodynamic control at room temperature in water media upon incubation with Fe(II) ions. Controlling the metal center configuration in helicates usually requires demanding synthetic procedures for obtaining chiral organic ligands, ${ }^{24}$ which complicates the access to multiple structural variants that are required for the systematic studies involved in the optimization of their biological properties. In our approach, however, the chirality of the peptide helicates arises naturally from two single Pro residues located in the loops connecting the three bisBpy substrands (Scheme 1). 
The chiral peptide helicates seem to be very stable in water at room temperature, as no degradation or racemization processes were detected for several weeks. We also performed thermal denaturation experiments in which the changes in absorbance at $525 \mathrm{~nm}$ were monitored upon increasing the temperature from 20 to $100{ }^{\circ} \mathrm{C}$. The sigmoidal melting profiles observed for both helicates were consistent with cooperative transitions in the decomplexation of the Fe(II) ions (Figure 2, and ESI). Both melting curves were qualitatively similar; with a $T_{m}$ temperature of $\approx 80.5^{\circ} \mathrm{C}$. Van't Hoff analysis of the thermal denaturation afforded the enthalpic and entropic changes of the unfolding process. As expected, the unfolding process of the helicate displays a positive entropic variation $(\Delta S \approx 447.1$ $\mathrm{J} / \mathrm{mol}$ ), consistent with the increase in molecular disorder resulting from the disassembly of the complexes; the unfolding process is also highly endothermic $(\Delta H \approx 157.9 \mathrm{~kJ} / \mathrm{mol})$, in agreement with the large association constants obtained in the $\mathrm{UV} / \mathrm{Vis}$ titrations and reported studies of related supramolecular metal complexes. ${ }^{25}$ Alternatively, global analysis of the unfolding process using the Gibbs-Helmholtz equation provided qualitatively similar results. ${ }^{26}$

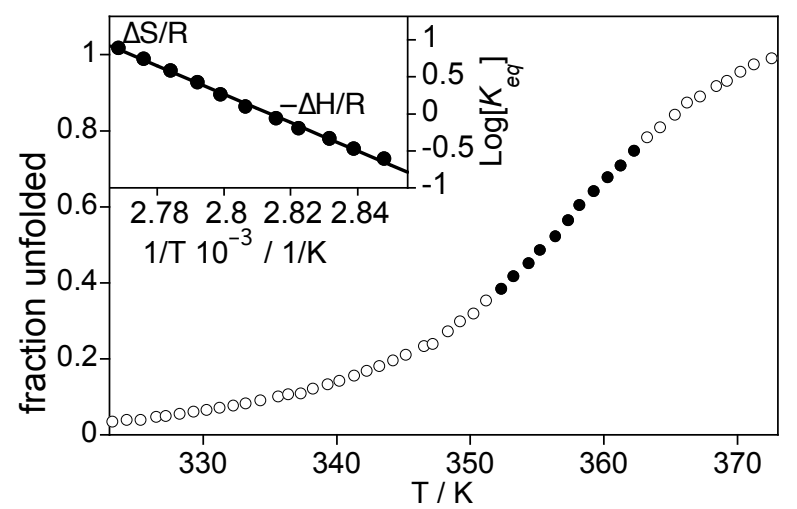

Figure 2. Left: Thermal denaturation curve and Van't Hoff analysis of the thermal denaturation process of a $7 \mu \mathrm{M}$ solution of $\Lambda \Lambda-\left[\mathrm{Fe}_{2}(\mathrm{LL}-\mathrm{H})\right]^{4+}$ in PBS buffer $10 \mathrm{mM}, \mathrm{NaCl} 10 \mathrm{mM}, \mathrm{pH}$ 7.2. Black points represent the data near the transition used in the Van't Hoff plot shown in the inset.

Having at hand the methodology for the efficient assembly of water-stable and optically pure peptide helicates, we decided to explore the DNA binding properties of these species. In particular, we were interested in studying the affinity and chiral selectivity of their binding to three-way DNA junction, ${ }^{27}$ data that remain unknown until now.

Towards this end, we synthesized the N-terminal rhodamine labeled derivatives of the previously described LL-H and DD-H peptide ligands. In short, once the core peptide sequences were fully assembled, and still attached to the solid support, their Nterminal amines were reacted with 5-(and 6)-carboxy-Xrhodamine succinimidyl ester to yield the fluorescent peptidic ligands LL-RhH and DD-RhH, which were then cleaved from the resin and purified as described before, and incubated with 2 eq. of $\mathrm{Fe}(\mathrm{II})$ to form the corresponding fluorescent helicates $\Lambda \Lambda-\left[\mathrm{Fe}_{2}(\mathbf{L L}-\mathbf{R h H})\right]^{4+}$ and $\Delta \Delta-\left[\mathrm{Fe}_{2}(\mathbf{D D}-\mathbf{R h H})\right]^{4+}$ (Scheme 2$)$.

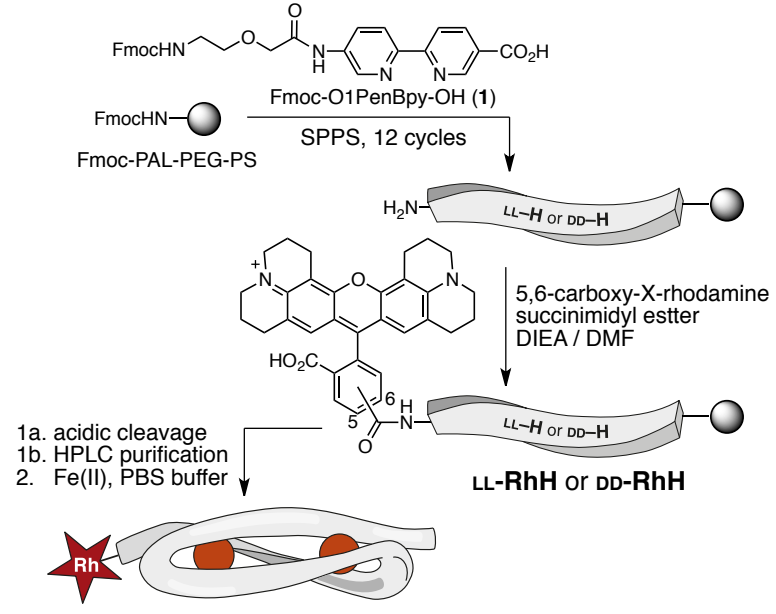

$\Lambda \Lambda-\left[\mathrm{Fe}_{2}(\mathrm{LL}-\mathrm{RhH})\right]^{4+}$ or $\Delta \Delta-\left[\mathrm{Fe}_{2}(\mathrm{DD}-\mathrm{RhH})\right]^{4+}$

Scheme 2. Solid phase peptide synthesis of the Rhodamine-labeled peptide ligands LL-RhoH and DD-RhoH by solid phase modification of the core peptides, and their corresponding helicates $\left(M-\left[\mathrm{Fe}_{2}(\mathrm{LL}-\mathrm{RhoH})\right]^{4+}\right.$ or $\Delta \triangle-\left[\mathrm{Fe}_{2}(\mathrm{DD}-\mathrm{RhoH})\right]^{4+}$ respectively). See Scheme 1 for complete sequences of LL-H and DD-H.

Incubation of $1 \mu \mathrm{M}$ solutions of the rhodamine-labeled helicates with increasing concentrations of the DNA three-way junction $\mathbf{Y}_{1} \mathbf{Y}_{2} \mathbf{Y}_{3}$ (see ESI) produced a concentration-dependent increase in the fluorescence anisotropy that could be fitted to a modified 1:1 binding mode, including higher order aggregates resulting from non-specific interactions (Figure 3). ${ }^{14}$ The $\Lambda \Lambda-$ $\left[\mathrm{Fe}_{2}(\mathbf{L L}-\mathbf{R h H})\right]^{4+}$ peptide helicate displayed significantly higher affinity-almost 150 fold-for the $\mathbf{Y}_{1} \mathbf{Y}_{2} \mathbf{Y}_{3}$ DNA junction than the enantiomeric $\Delta \Delta-\left[\mathrm{Fe}_{2}(\mathbf{D D}-\mathbf{R h H})\right]^{4+}$, with apparent dissociation constants for the $1: 1$ complexes of $0.25 \pm 0.04 \mu \mathrm{M}$ and $37.6 \pm 1.0 \mu \mathrm{M}$, respectively. ${ }^{28}$
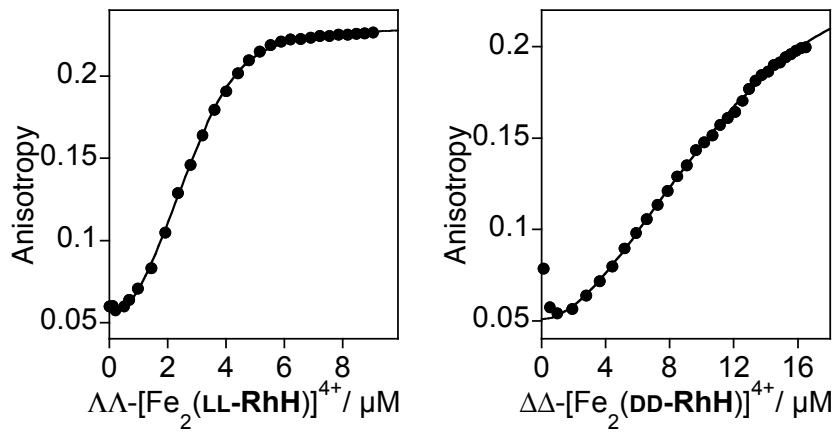

Figure 3. Fluorescence anisotropy titrations of $1 \mu \mathrm{M}$ solutions of peptidic helicates with a DNA three-way junction $\left(\mathbf{Y}_{1} \mathbf{Y}_{2} \mathbf{Y}_{3}\right)$ in $10 \mathrm{mM}$ phosphate buffer, $\mathrm{NaCl} 10 \mathrm{mM} ; \mathrm{pH}: 7.3,20$ ㅇ. $\Lambda \wedge-\left[\mathrm{Fe}_{2}(\mathrm{LL}-\mathrm{RhH})\right]^{4+}$ (left) and $\Delta \Delta-\left[\mathrm{Fe}_{2}(\mathrm{DD}-\mathrm{RhH})\right]^{4+}$ (right). Lines represent the best fit to $1: 1$ binding models including the contribution of nonspecific electrostatic complexes. DNA oligo sequences: $Y_{1}: 5^{\prime}-$ CAC CGC TCT GGT CCT C-3'; $Y_{2}$ : 5'-CAG GCT GTG AGC GGT G-3'; $\mathbf{Y}_{3}$ : 5'-GAG GAC CAA CAG CCT G-3'.

In summary, herein we present a simple and versatile methodology for the enantioselective assembly of water-stable and DNA-binding helicates. This novel approach relies in the modularity and synthetic flexibility of solid-phase peptide synthesis and in the preorganization of the peptide ligand provided by two single proline residues, which also encode the 
helical chirality of their corresponding helicates formed under thermodynamic control in water media in the presence of Fe(II) ions. We have demonstrated the potential of this approach synthesizing fluorescently-labeled helicates that show chiral discrimination and high selectivity for three-way DNA junctions.

We are thankful for the support given by the Spanish grants SAF2010-20822-C02， CTQ2012-31341， CTQ2011-23336, CCTQ2010-16959 Consolider Ingenio 2010 CSD2007-00006, the Xunta de Galicia, GRC2010/12, GRC2013-041, PGIDIT08CSA-047209PR, the Generalitat de Catalunya, 2009SGR68. Support of COST Action CM1105 is kindly acknowledged. G.R. thanks the INL for his PhD fellowship and E. O. the UAB for her Ph. D. grant. M. V.-L. dedicates this work to his newborn and third son, Iván.

${ }^{a}$ Departamento de Química Inorgánica, ${ }^{c}$ Departamento de Química Orgánica, and Centro Singular de Investigación en Química Biolóxica e Materiais Moleculares (CiQUS). Universidade de Santiago de Compostela. 15782 Santiago de Compostela, Spain. E-mail: miguel.vazquez.lopez@usc.es or eugenio.vazquez@usc.es

${ }^{b}$ Departament de Química. Universitat Autònoma de Barcelona, 08193 Cerdanyola, Spain

Electronic Supplementary Information (ESI) available: synthetic procedures and characterization of peptide ligands and helicates, computational details, spectroscopic studies (UV, CD, melting). See DOI: $10.1039 / \mathrm{c} 000000 \mathrm{x} /$

\section{Notes and references}

1 a) Pazos, E.; Mosquera, J.; Vazquez, M. E.; Mascareñas, J. L. ChemBioChem, 2011, 12, 1958; c) Højfeldt, J. W.; Van Dyke, A. R.; Mapp, A. K. Chem. Soc. Rev., 2011, 40, 4286.

2 a) P. P. Pandolfi, Oncogene 2001, 20, 3116; b) R. Pollock, M. Giel, K. Linher, T. Clackson, Nature Biotechnol., 2002, 20, 729.

3 Metal Complex-DNA Interactions, Eds. N. Hadjiliadis and E. Sletten. Wiley, Chichester, UK, 2009.

4 a) C. Piguet, G. Bernardinelli and G. Hopfgartner, Chem. Rev. 1997, 97, 2005; b) M. Albrecht, Chem. Rev., 2001, 101, 3457.

5 I. Meistermann, V. Moreno, M. J. Prieto, E. Moldrheim, E. Sletten, S. Khalid, P. M. Rodger, J. C. Peberdy, C. J. Isaac, A. Rodger and M J. Hannon, Proc. Natl. Acad. Sci. USA, 2002, 99, 5069.

6 G. Oleski, A. G. Blanco, R. Boer, I. Usón, J. Aymamí, A. Rodger, M. J. Hannon and M. Coll, Angew. Chem. Int. Ed., 2006, 45, 1227.

7 J. M. Lehn, A. Rigault, J. Siegel, J. Harrowfield, B. Chevrier, D Moras, Proc. Natl. Acad. Sci. USA, 1987, 84, 2565-2569.

8 E. Terrazzi, L. Guénée, J. Varin, B. Bocquet, J.-F. Lemmonier, D. Emery, J. Mareda and C. Piguet., Chem. Eur. J., 2011, 17, 184.

9 a) M. J. Hannon, I. Meistermann, C. J. Isaak, C. Blomme, J. R. Aldrich-Wright and A. Rodger, Chem. Commun., 2001, 1078; b) N. Ousaka, Y. Takeyama and E. Yashima, Chem. Sci., 2012, 3, 466.

10 M. R. Bermejo, A. M. González-Noya, R. M. Pedrido, M. J. Romero and M. Vázquez, Angew. Chem. Int. Ed., 2005, 44, 4182.

11 L. Cardo, V. Sadovnikova, S. Phongtongpasuk, N. J. Hodges and M. J. Hannon, Chem. Commun., 2011, 47, 6575.
12 S. E. Howson, A. Bolhuis, V. Brabec, G. J. Clarkson, J. Malina, A. Rodger and P. Scott, Nature Chem., 2012, 4, 31.

13 a) M. I. Sánchez, O. Vazquez, M. E. Vázquez, and J. L. Mascareñas, Chem. Eur. J., 2013, 19, 9923; b) M. I. Sánchez, O. Vazquez, J. Martinez-Costas, M. E. Vazquez, and J. L. Mascareñas, Chem. Sci., $2012,3,2383$.

14 M. I. Sánchez, O. Vazquez, M. E. Vázquez, and J. L. Mascareñas, Chem. Eur. J., 2013, 19, 9923-9929.

15 a) I. Gamba, I. Salvadó, G. Rama, M. Bertazzon, M. I. Sánchez, V. M. Sánchez-Pedregal, J. Martinez-Costas, R. F. Brissos, P. Gamez, J. L. Mascareñas, M. Vázquez López, and M. E. Vázquez, Chem. Eur. J., 2013, 19, 13369; b) G. Rama, A. Ardá, J.-D. Maréchal, I. Gamba, H. Ishida, J. Jiménez-Barbero, M. E. Vazquez, and M. Vázquez López, Chem. Eur. J., 2012, 18, 7030.

16 C. Kaes, A. Katz and M. W. Hossein, Chem. Rev. 2000, 100, 3553.

17 I. Coin, M. Beyermann, and M. Bienert, Nature Prot., 2007, 2, 3247.

18 The overall formation constants are represented by the $\beta_{\mathrm{m}, \mathrm{n}}$ notation, where $\mathrm{m}$ and $\mathrm{n}$ refer to the stoichiometry of the metal ion and the ligand, respectively. Thus, $\beta_{\mathrm{m}, \mathrm{n}}=\beta\left(\mathrm{M}_{\mathrm{m}} \mathrm{L}_{\mathrm{n}}\right)=\left[\mathrm{M}_{\mathrm{m}} \mathrm{L}_{\mathrm{n}}\right] /\left([\mathrm{M}]_{\mathrm{m}}[\mathrm{L}]_{\mathrm{n}}\right)$.

19 a) R. Binstead and A. Zuberbühler, SPECFIT/32 Global Analysis System, TgK Scientific Limited; b) H. Gampp, M. Maeder, C. J. Meyer and A. D. Zuberbühler, Talanta 1985, 32, 257; c) H. Gampp, M. Maeder, C. J. Meyer and A. D. Zuberbühler, Talanta 1986, 33, 943.

20 These reported binding constants are only rough estimations, limited by the relatively high concentrations required for the $U V / v i s$ titrations: P. Thordarson, Chem. Soc. Rev. 2011, 40, 1305

21 a) M. Albrecht, O. Spiess, M. M. Schneider, P. Weis, Chem. Commun., 2002, 38, 786; b) N. Ousaka, Y. Takeyama, E. Yashima, Chem. Sci., 2012, 3, 466; c) E. C. Constable, C. E. Housecroft, S. Mundwiler, J. Chem. Soc., Dalton Trans. 2003, 2112; d) L. Cardo, V. Sadovnikova, S. Phongtongpasuk, N. J. Hodges, M. J. Hannon, Chem. Commun., 2011, 47, 6575; e) M. Albretch in Metallofoldamers: Supramolecular Architectures from Helicates to Biomimetics (Eds.: M. Albretch and H. Maayan), Jon Wiley \&Sons, Ltd., Chichester, 2013, 275.

22 M. Ziegler and A. von Zelewsky, Coord. Chem. Rev., 1998, 177, 257.

23 Studies with related mononuclear metallopeptides support the high enantioselectivity in the formation of the metal complexes derived from chiral peptides.

24 O. Mamula, A. von Zelewsky, P. Brodard, C.-W. Schläpfer, G. Bernardinelly, H. Stoeckli-Evans, Chem. Eur. J., 2005, 11, 3049.

25 M. Ashram, M. Bqaeen and S. Mizyed, J. Incl. Phenom. Macro. Chem., 2010, 67, 81 .

26 a) N. J. Greenfield, Nature Prot., 2006, 1, 2527; b) J. L. Neira, M. E. Vazquez and A. R. Fersht, Eur. J. Biochem,. 2000, 267, 2859.

27 Q. Guo, M. Lu, M. E. Churchill, T. D. Tullius and N. R. Kallenbach, Biochemistry, 1990, 29, 10927.

28 We previously synthesized the corresponding fluorescein analogs, $\Lambda \Lambda-\left[\mathrm{Fe}_{2}(\mathbf{L L}-\text { FluH })\right]^{4+}$ and $\Delta \Delta-\left[\mathrm{Fe}_{2}(\mathbf{D D}-\mathrm{FluH})\right]^{4+}, \quad$ which unfortunately were poorly soluble in water. 